JMI Vol. 41 No. 2, Desember 2019

METAL INDONESIA

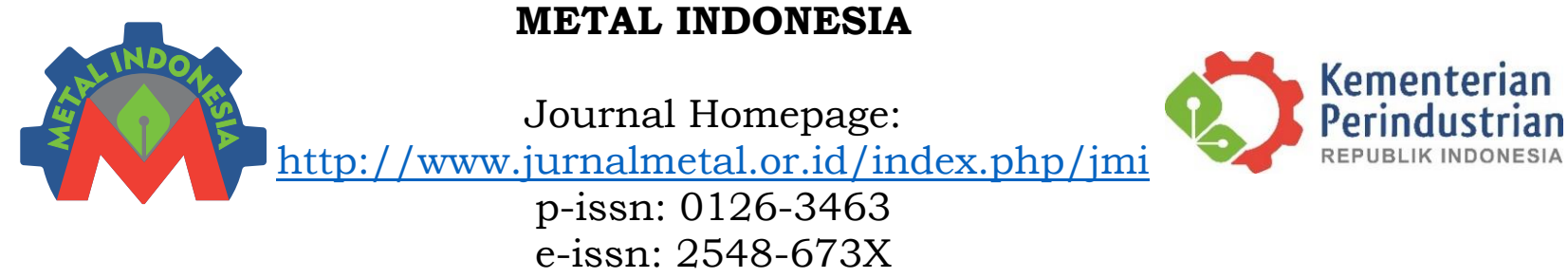

\title{
PENGARUH VARIASI WAKTU HOLDING PROSES ARTIFICIAL AGING TERHADAP KEKUATAN TARIK DAN KETAHANAN IMPAK PADUAN Al-Si
}

\section{EFFECT OF HOLDING TIME DURING ARTIFICIAL AGING OF AL-SI ALLOY ON TENSILE AND IMPACT STRENGTH}

\author{
Moch Iqbal Zaelana Muttahar ${ }^{1}$, Purbaja Adi Putra ${ }^{2}$, Greida Frista ${ }^{3}$ \\ ${ }^{1,2,3}$ Balai Besar Logam dan Mesin, Badan Penelitian dan Pengembangan Industri, \\ Kementerian Perindustrian, Jl. Sangkuriang 12 Dago Bandung, Indonesia \\ Email: ${ }^{1}$ mochiqbal@kemenperin.go.id
}

\begin{abstract}
Abstrak
Indonesia menjadi salah satu negara dengan konsumsi aluminium terbesar, salah satunya untuk komponen bogie tank baja. Upaya pembuatan roda bogie wheel telah dilakukan dengan berbagai metode, salah satunya adalah proses pengecoran. Untuk memenuhi spesifikasi teknis tersebut, bogie hasil pengecoran harus dikenai proses heat treatment agar memiliki sifat mekanik yang memadai. Dalam penelitian ini dilakukan variasi waktu holding proses artificial aging selama 2, 3, 4, dan 5 jam. Pengujian yang dilakukan berupa uji metalografi, pengujian tarik, dan pengujian impak. Hasil dari pengujian, didapatkan bahwa kekuatan tertinggi adalah sebesar 193,08 MPa yang dicapai oleh spesimen aluminium dengan waktu holding proses artificial aging selama 5 jam. Ketahanan impak tertinggi adalah sebesar 2,55 Joule yang dicapai oleh spesimen aluminium dengan waktu holding proses artificial aging selama 5 jam. Presipitat yang terbentuk pada hasil artificial aging berupa presipitat AlSi yang halus, membulat dan membentuk kluster.

Kata kunci: Aluminium, Perlakuan Panas, Aging, Presipitat

Abstract

Indonesia is one of the countries with the largest aluminum consumption, particularly for bogie tracklink tank components. The efforts to make bogie wheel wheels have been carried out with various methods, including the casting process. There are some technical specifications to support bogie on its application, bogies from casting must be subjected to a heat treatment process in order to have adequate mechanical properties. In this research, the variation of holding time of the artificial aging process was 2, 3, 4, and 5 hours. Tests carried out in the form of metallographic, tensile strength testing, and impact testing. It was found that the highest strength was 193.08 MPa which was achieved by aluminum specimen with holding time for the artificial aging process for 5 hours. The highest impact resistance is 2.55 Joules which is achieved by aluminum specimens with a holding time of the artificial aging process for 5 hours. Precipitates that are formed on the results of artificial aging are AlSi precipitates with smooth, rounded and clustered shape.
\end{abstract}

Keywords: Aluminum, Heat Treatment, Aging, Precipitate 


\section{PENDAHULUAN}

Aluminium merupakan salah satu logam non-ferrous dengan konsumsi tertinggi di dunia, dengan konsumsi tahunan bisa mencapai hingga angka 24 juta ton/tahun. (Totten dan MacKenzie 2003) Di Indonesia permintaan aluminium terus meningkat, pada tahun 2016 diperkirakan konsumsi aluminium akan mencapai angka 800 ribu ton/tahun. (Laporan Tahunan INALUM 2015)

Salah satu pengunaan aluminium di Indonesia adalah sebagai material penyusun bagian roda tank baja (bogie). Bogie adalah bagian lempeng roda yang mengalami kontak langsung dengan rantai pada sistem penggerak tank baja. Hal ini menyebabkan material yang akan digunakan untuk bogie tank baja harus memiliki sifat mekanik yang cukup tinggi untuk menahan segala beban yang terjadi pada bogie tersebut. Salah satu sifat pendukung nya adalah kuat tariknya sebesar $228 \mathrm{MPa}$. (Gabrian International (H.K.) Ltd. n.d.)

Pada prinsipnya material hasil pengecoran perlu melalui proses heat treatment untuk meningkatkan sifat mekanik produk cor yang akan digunakan. Proses perlakuan yang tepat dilakukan pada paduan aluminium adalah proses precipitation hardening yang melibatkan proses artificial aging. (Alcan 2008)

Artificial aging merupakan salah satu metode treatment pada aluminium yang bertujuan untuk mempercepat laju pertumbuhan presipitat sehingga sifat mekanik dari aluminium dapat disesuaikan dan dicapai akibat tumbuhnya presipitat pada proses ini. Kombinasi temperatur dan waktu tahan proses artificial aging akan sangat menentukan sifat mekanik dari material yang dikenai treatment. (Pranata, Alfirano and Mujiat n.d.) Maka dari itu penelitian ini bertujuan untuk mengamati pengaruh temperatur dan waktu tahan aging terhadap perubahan strukutur mikro dan perubahan sifat mekanis berupa kekuatan tarik dan ketahanan impak paduan $\mathrm{Al}-\mathrm{Si}$ hasil pengecoran untuk material bogie wheel.

\section{METODOLOGI PENELITIAN}

\section{Sampel}

Paduan Al-Si yang digunakan dalam penelitian ini berasal dari proses pengecoran. Preparasi sampel dilakukan melalui proses pemesinan dengan machining pada beberapa bagian test piece agar didapatkan test piece yang sesuai standar uji. Komposisi spesimen ditunjukkan pada Tabel 1.

\section{Heat Treatment}

Proses heat treatment diawali dengan proses solid solution treatment (SST). Pada langkah ini spesimen uji dipanaskan di dalam furnace hingga temperatur $540{ }^{\circ} \mathrm{C}$, dilakukan penahanan temperatur SST selama 5 jam. (Afifi, Wang and Pereira 2018) Proses pendinginan (quenching) dilakukan dengan menggunakan media air pada temperatur $65-80{ }^{\circ} \mathrm{C}$ selama 10 menit. Langkah terakhir yaitu artificial aging. Pada langkah ini spesimen uji dipanaskan di dalam furnace hingga temperatur $155^{\circ} \mathrm{C}$ dengan variasi holding time 2 jam, 3 jam, 4 jam dan 5 jam. (Xu, Zheng and Li 2017) Kemudian dikeluarkan dari tungku hingga temperatur material mendekati temperatur kamar.

Tabel 1. Komposisi Paduan Al-Si

\section{Unsur Komposisi (\%)}

\begin{tabular}{cc}
\hline $\mathbf{A l}$ & 88,80 \\
\hline $\mathbf{S i}$ & 6,38 \\
\hline $\mathbf{F e}$ & 1,54 \\
\hline $\mathbf{C u}$ & 1,21 \\
\hline $\mathbf{M n}$ & 0,11 \\
\hline $\mathbf{M g}$ & 0,06 \\
\hline $\mathbf{C r}$ & 0,04 \\
\hline $\mathbf{N i}$ & 0,11 \\
\hline $\mathbf{Z n}$ & 1,47 \\
\hline
\end{tabular}

Pengamatan Metalografi dan Scanning Electron Microscopy - Energy-dispersive Spectroscopy (SEM-EDS)

Uji metalografi bertujuan untuk mengetahui struktur mikro dan fasa-fasa yang terbentuk sebelum dan sesudah dilakukannya proses heat treatment pada spesimen uji. Standar yang digunakan pada pengujian metalografi adalah ASTM 340. Etsa yang digunakan berupa keller's reagent dengan komposisi $95 \%$ air, 2,5\% $\mathrm{HNO}_{3}, 1,5 \% \mathrm{HCl}$, dan $1 \% \mathrm{HF}$. (Brandes and Brook 2001) sedangkan untuk SEM-EDS menggunakan standar ASTM E986-04. 


\section{Uji Tarik}

Uji tarik adalah pengujian yang bertujuan untuk mengetahui kekuatan material ketika dikenai beban dalam besaran tertentu. Dalam pengujiannya, spesimen uji disesuaikan dengan standar uji tarik JIS Z 2201 no. 5. Berdasarkan standar tersebut didapatkan panjang spesimen uji adalah sebesar $120 \mathrm{~mm}$, gauge length sepanjang $50 \mathrm{~mm}$, dan diameter gauge adalah $14 \mathrm{~mm}$ seperti ditunjukkan Gambar.1. (Setyawan, Irawan and Suprapto 2014)

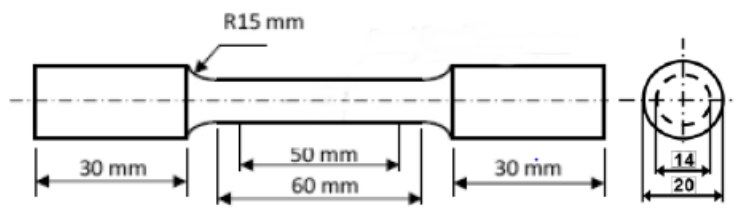

Gambar 1. Spesimen uji tarik standar JIS 2201

\section{Uji Impak}

Uji impak (ketangguhan) adalah suatu pengujian yang dilakukan untuk mengetahui kemampuan suatu bahan dalam menyerap energi sebelum patah. Spesimen uji disesuaikan dengan standar uji impak JIS Z 2242. Berdasarkan standar tersebut didapatkan ukuran spesimen uji adalah $55 \times 10 \times 10 \mathrm{~mm}$ dengan notch berbentuk $\mathrm{v}$ dan sudut notch sebesar $45^{\circ}$ yang ditunjukkan pada Gambar 2. (JIS Z 2242 - Impact Testing 2005)
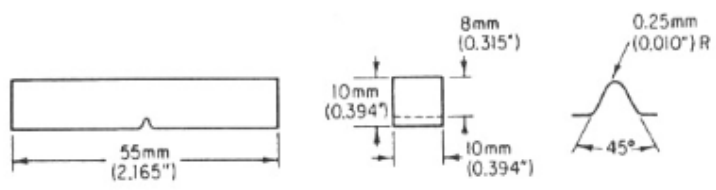

Simple beam $V$-notched Charpy type

Gambar 2. Spesimen uji impak JIS Z 2242

\section{HASIL DAN PEMBAHASAN}

Analisa pengaruh waktu holding artificial aging terhadap mikrostruktur

Pengamatan mikrostruktur ditunjukkan pada

Gambar 3. Pengamatan dilakukan menggunakan mikroskop optik dengan perbesaran $500 \times$. Pada hasil mikrostruktur tanpa treatment masih terlihat adanya dendrit pertumbuhan butiran akibat hasil dari proses pengecoran. Dendrit ini didominasi oleh silikon yang dipicu oleh partikel pengotor, mekanisme ini terjadi akibat adanya paduan yang tidak dimodifikasi sehingga menjadi interface pengintian yang berulang yang menyebabkan adanya simpangan yang terbentuk akibat twinning kristal kubik di antarmuka pemadatan. (Shievkumer, Wang and Keller 1994)

Pada hasil mikrostruktur dapat dilihat bahwa terjadi perubahan struktur pada paduan Al$\mathrm{Si}$ hasil aging. Sebelum dilakukan proses heat treatment belum terlihat adanya presipitat yang muncul, namun pada saat artificial aging telah dilakukan terlihat munculnya presipitat dengan senyawa AlFeSi dan AlSi pada mikrostruktur aluminium. Hal ini didukung dengan hasil SEM yang ditunjukkan pada Gambar 4.

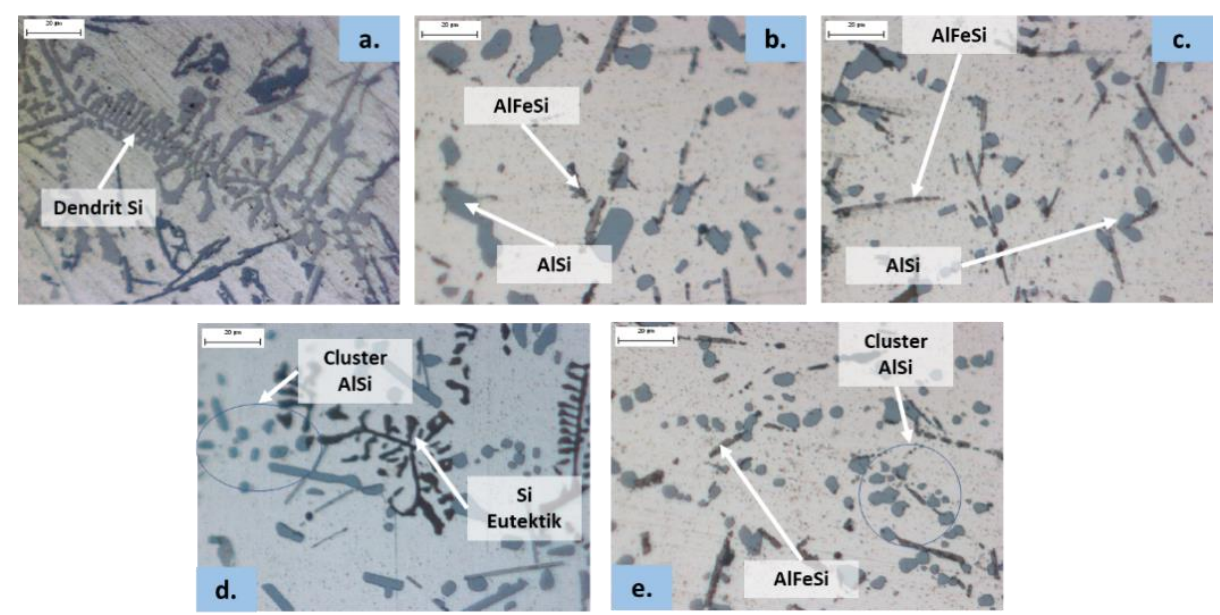

Gambar 3. Mikrostruktur spesimen paduan Al-Si a. as cast b. Holding 2 jam c. Holding 3 jam d. Holding 4 jam e. Holding 5 jam 
Pada waktu holding selama 2 jam, presipitat yang terbentuk masih berukuran besar dan kasar. Semakin lama waktu holding presipitat yang terbentuk cenderung lebih halus dan tersebar. (Djatmiko and Budiarto 2007) Hal ini terjadi karena persipitat terus terbentuk pada temperatur aging. Presipitat tersebut relatif terbentuk pada suhu aging $155{ }^{\circ} \mathrm{C}$, sehingga mampu memberikan kontribusi terhadap kekuatan karena bersifat koheren terhadap matriksnya. Semakin koheren suatu presipitat terhadap matriksnya maka dislokasi akan menjadi lebih sulit merambat. (Djatmiko and Budiarto 2007) hal ini menyebabkan dibutuhkannya energi yang lebih besar untuk menggerakan dislokasi, sehingga material akan menjadi lebih kuat.
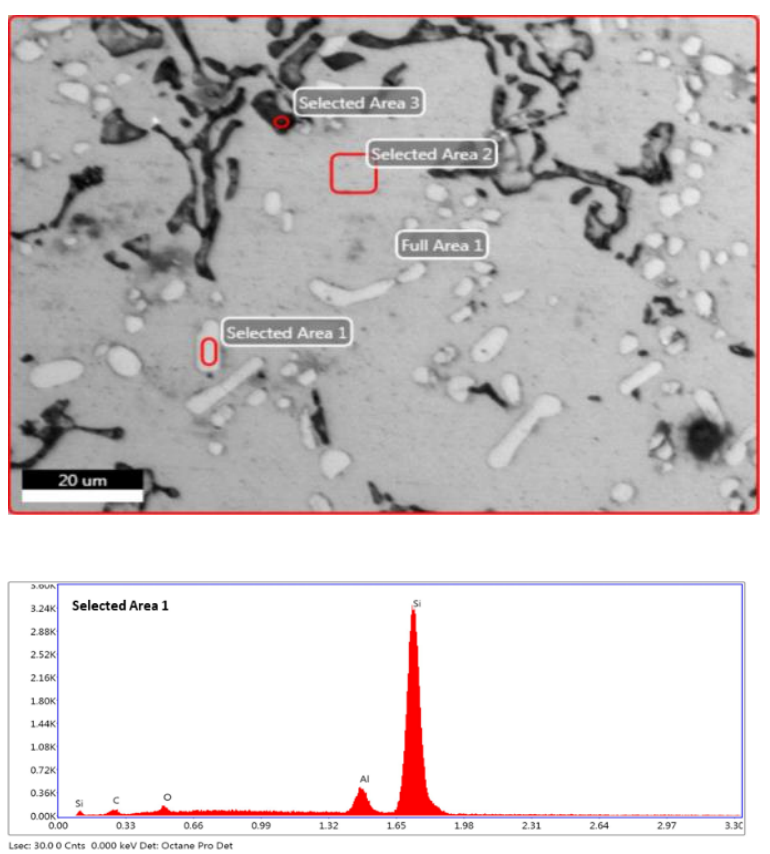

\begin{tabular}{ccc} 
Element & Weight \% & Atomic \% \\
\hline C K & 3.03 & 6.73 \\
\hline OK & 1.23 & 2.06 \\
AlK & 7.77 & 7.68 \\
\hline SiK & 87.97 & 83.53
\end{tabular}

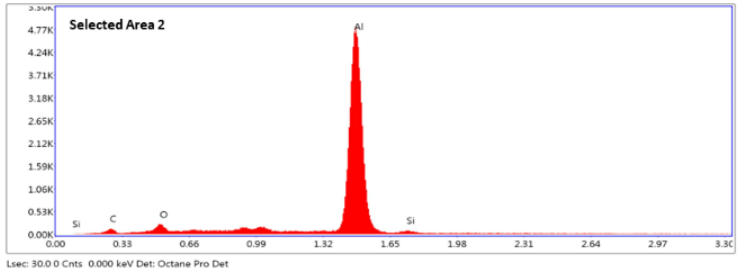

\begin{tabular}{|ccc|} 
Element & Weight \% & Atomic \% \\
\hline C K & 3.03 & 6.73 \\
\hline O K & 1.23 & 2.06 \\
\hline AlK & 7.77 & 7.68 \\
\hline SiK & 87.97 & 83.53 \\
\hline
\end{tabular}

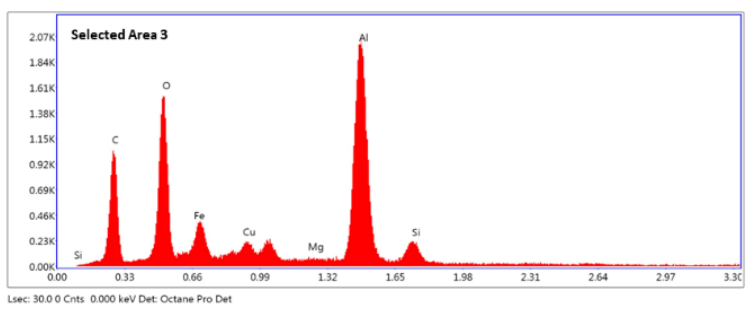

\begin{tabular}{|c|c|c|}
\hline lement & Weight $\%$ & tomic \\
\hline $\mathrm{CK}$ & 19.15 & 33.13 \\
\hline OK & 17.62 & 22.89 \\
\hline $\mathrm{FeL}$ & 7.34 & 2.73 \\
\hline CuL & 3.71 & 1.21 \\
\hline MgK & 0.30 & 0.26 \\
\hline AlK & 45.98 & 35.41 \\
\hline SiK & 5.90 & 4.37 \\
\hline
\end{tabular}

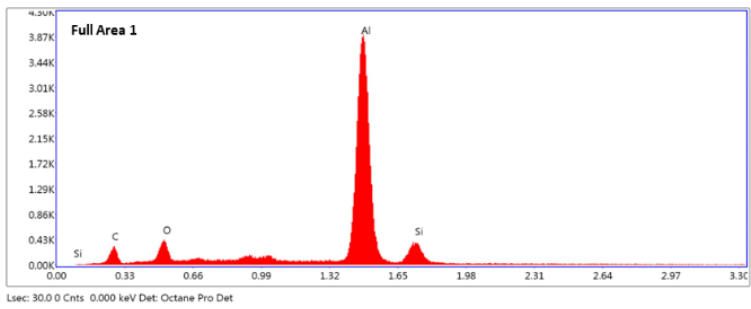

\begin{tabular}{|c|c|c|}
\hline \multicolumn{3}{|c|}{ Element Weight \%Atomic $\%$} \\
\hline $\mathrm{CK}$ & 6.84 & 13.83 \\
\hline $\mathrm{OK}$ & 4.36 & 6.62 \\
\hline AlK & 78.54 & 70.68 \\
\hline SiK & 10.26 & 8.87 \\
\hline
\end{tabular}

Gambar 4. Hasil SEM-EDS sampel paduan aluminium dengan perlakuan aging selama 5 jam 
Pada temperatur waktu holding selama 4 dan 5 jam persipitat menjadi lebih halus, membulat serta cenderung membentuk kluster. Hal ini membuat sifat mekanis aluminium mendekati nilai optimum. (Shievkumer, Wang and Keller 1994)

Presipitat AlFeSi terlihat dari bentuk yang menjarum, Sementara untuk presipitat AlSi cenderung menjadi presipitat yang bulat. (Brandes and Brook 2001)

Analisa pengaruh waktu holding artificial aging terhadap kuat Tarik

Nilai kuat Tarik spesimen sebelum proses HT dilakukan adalah sebesar 151,18 MPa seperti ditunjukkan pada Gambar 5. Nilai ini lebih tinggi jika dibandingkan dengan spesimen yang digunakan pada penelitian masy'ari, (Masy'ari 2011) hal ini disebabkan karena kandungan Fe 1 $\%$ lebih tinggi pada paduan aluminium yang digunakan pada penelitian ini. (Masy'ari 2011) semakin tinggi kandungan $\mathrm{Fe}$ maka kekuatan tariknya akan menjadi lebih tinggi karena disebabkan oleh terbentuknya presipitasi AlFeSi yang mampu menghalangi pergerakan dislokasi. (Davis 2001)

Hasil uji tarik pada spesimen dengan perlakuan aging selama 2 hingga 5 jam mengalami kenaikan secara konstan dari 175,29 hingga 193,08 MPa. Hal ini disebabkan karena presipitat AlSi yang mulai menyebar sehingga menyebabkan jarak antar atom aluminium menjadi semakin kecil sehingga atom aluminium memiliki ikatan yang relatif lebih kuat. (Masy'ari 2011)

Analisa pengaruh waktu holding artificial aging terhadap ketahanan impak

Nilai ketahanan impak spesimen tanpa heat treatment adalah sebesar 0,59 J yang ditunjukkan pada Gambar 6. Nilai ketahanan impak setelah dikenai heat treatment terus meningkat hingga 2,55 J. Hal ini terjadi karena kristal silikon mengalami penurunan ukuran dan membentuk morfologi yang membulat sehingga mampu meningkatkan ketahanan terhadap retak pada paduan. (Shievkumer, Wang and Keller 1994)

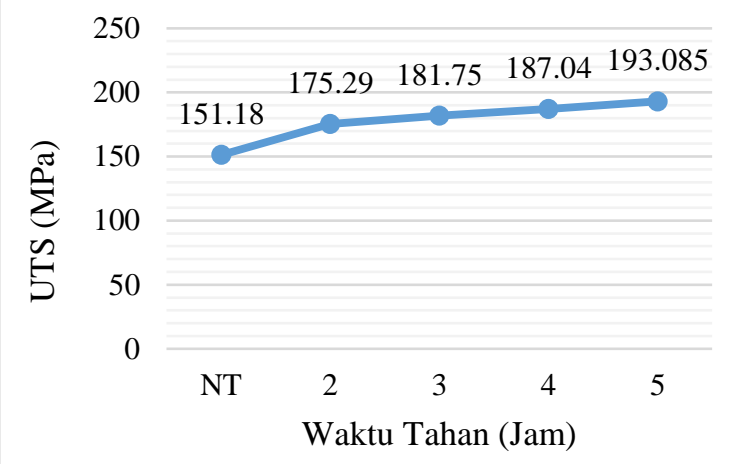

Gambar 5. Perbandingan nilai kuat tarik dari spesimen tanpa treatment (NT) dan yang dikenai variasi holding time artificial aging

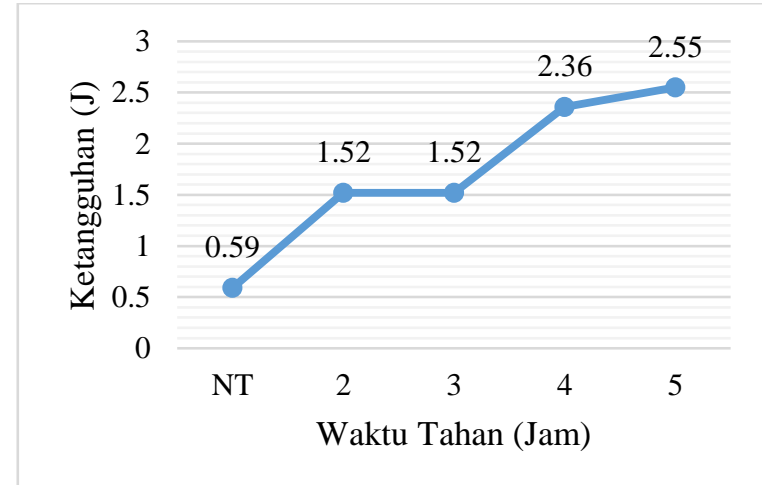

Gambar 6. Perbandingan nilai ketahanan impak dari spesimen tanpa treatment (NT) dan yang dikenai variasi holding time artificial aging

\section{KESIMPULAN}

Dari hasil penelitian yang telah dilakukan, dapat disimpulkan bahwa dengan waktu holding proses artificial aging selama 5 jam didapatkan kekuatan sebesar 193,08 MPa dan ketahanan impak sebesar 2,55 Joule. Presipitat yang terbentuk pada hasil artificial aging berupa presipitat AlFeSi yang menjarum dan AlSi yang berbentuk bulat serta membentuk kluster yang mendukung penghambatan dislokasi yang terjadi sehingga membentuk material yang lebih kuat.

\section{UCAPAN TERIMA KASIH}

Penulis mengucapkan terima kasih Kepala Balai Besar Logam dan Mesin dan Ibu Shinta Virdhian (Kepala Bidang Penelitian dan Pengembangan, BBLM), Bapak Dagus Resmana Djuanda, dan Ibu Eva Afrilinda yang telah 
berkenan untuk memberikan bantuan dan fasilitas untuk mendukung dalam kegiatan penelitian ini.

\section{DAFTAR PUSTAKA}

Afifi, Mohamed, Ying Chun Wang, and Pedro Henrique $R$ Pereira. "Effect of heat treatments on the microstructures and tensile properties of an ultrafine-grained $\mathrm{Al}-\mathrm{Zn}-\mathrm{Mg}$ alloy processed by ECAP." Journal of Alloys and Compounds 749 (2018): 567-574.

Alcan, Rio Tinto. Heat Treatment of Alumunium Foundry Alloy. Alcan International Ltd, 2008.

Brandes, E. A., and G. B. Brook. Smithells Metals Reference Book. Oxford: Elsevier, 2001.

Davis, J. R. "Aluminum and Alumunium Alloys." In Alloying : Understanding The Basics, 351-416. ASM International, 2001.

Djatmiko, Eddy, and Budiarto. "Pengaruh Perlakuan Panas T6 Terhadap Kekerasan Dan Strukturmikro Pada Paduan Al-SiMg." Materi Indonesia, 2007: 78-83.

Gabrian International (H.K.) Ltd. 7075 Aluminum Alloy: Properties. New Hampshire : Gabrian, n.d.

"JIS Z 2242 - Impact Testing." In Japanese Industrial Standard, 538. 2005.

Laporan Tahunan INALUM. Batu Bara: PT INALUM (Persero), 2015.

Masy'ari. Pengaruh Kecepatan Putar, Perlakuan Panas T6 dan Penambahan Inokulan AlTiB Pada Centrifugal Casting Terhadap Sifat Fisis dan Mekanis Al 356 Velg Sepeda Motor. Yogyakarta: Universitas Gadjah Mada, 2011.

Pranata, M D Endah, Alfirano, and Jajat Mujiat. "Analisis Struktur Mikro Dan Sifat Mekanik Paduan Al 2014 Hasil Proses Aging Dengan Temperatur Dan Waktu Tahan." Material, n.d.

Setyawan, Pungky Edy, Yudy Surya Irawan, and Wahyono Suprapto. "Kekuatan Tarik dan Porositas Hasil Sambungan Las Gesek Aluminium 6061 dengan Berbagai Suhu Aging." Jurnal Rekayasa Mesin volume 5 (2014): 141-148.

Shievkumer, S, L Wang, and C Keller. "Impact Properties of A356-T6 Alloys." Journal of Materials Engineering and
Performance 3, no. thoughness (1994): 83-90.

Shivkumar, Satya, F, S Wang, and C Keller. "Impact Properties of A356-T6 Alloys." Mechanical Engineering Faculty Publications (Department of Mechanical Engineering), 1994: 83-90.

Totten, George E, and D. Scott MacKenzie. Handbook of Alumunium Physical Metallurgy and Process. New York, Bassel: Marcel Dekker, Inc, 2003.

$\mathrm{Xu}$, Xuesong, Jingeu Zheng, and Zhi Li. "Precipitation in an $\mathrm{Al}-\mathrm{Zn}-\mathrm{Mg}-\mathrm{Cu}$ alloy during isothermal aging: Atomicscale HAADF-STEM investigation." Materials Science \& Engineering A 691 (2017): 6070. 